\title{
Structural and ultrastructural study of the rabbit kidney exposed to carbamate insecticide
}

\author{
Viera Almášiová, Katarína Holovská, Viera Cigánková \\ University of Veterinary Medicine and Pharmacy, Department of Anatomy, Histology and Physiology, \\ Košice, Slovak Republic
}

Received February 18, 2014

Accepted September 17, 2014

\begin{abstract}
The aim of the present study was to determine the influence of orally administered insecticide bendiocarb on the structure and ultrastructure of the kidney parenchyma in rabbits. Bendiocarb in the form of capsules ( $96 \%$ Bendiocarb, Bayer), at a dose of $5 \mathrm{mg} / \mathrm{kg}$ of body weight was fed daily for 3 days. After sampling, kidney sections of experimental and control animals were evaluated. Under a light and electron microscope the diffuse degenerative changes in kidney cortex and medulla were noted. Light microscopy revealed that the renal corpuscles had normal structure, but other nephron components and the collecting ducts were invariably changed. The epithelial cells inside the proximal and distal tubules and collecting ducts possessed increased quantity of cytoplasmic vacuoles and some tubular sections showed cellular sloughing and necrotization. The cells within the thin limbs of the Henley's loops had normal histological structure except for sporadic necrotizing cells within some segments. The ultrastructural evaluation showed extensive cytoplasmic vacuolisation and degenerative changes, such as mitochondrial swelling and shortening of basal infoldings within proximal and distal tubules, and microvilli reduction within proximal tubules. Cells of the collecting tubules exhibited a higher number of vacuoles and some cells had apparently reduced organelles. The cells of the thin limbs of the Henle's loop showed more vacuolised cytoplasm, some tubular sections revealed cellular detachment between the adjacent epithelial cells and rare necrotising epithelial cells were observed. The described findings addressed in the present study indicate an adverse effect of bendiocarb on the kidney parenchyma in rabbits.
\end{abstract}

Bendiocarb, pesticide, toxicity, morphology

WHO classified bendiocarb (2.2-dimethyl-1.3-benzodioxol-4-yl- $N$-methylcarbamate) as moderately dangerous to humans due to its acute toxicity after oral ingestion or absorption through the skin (WHO 2007). At present, bendiocarb is not approved for using in the European Union, but it is one of 12 insecticides recommended by the WHO for use in malaria control in Africa. In compliance with National Pesticide Information Centre the LD 50 for technical bendiocarb is $35-40 \mathrm{mg} / \mathrm{kg}$ for rabbits. In mammals the toxicity has been ascribed to their ability to inhibit acetylcholinesterases, catalysing the hydrolysis of the neurotransmitter acetylcholine.

According to Challis and Adcock (1981) 90\% of an oral bendiocarb dose was excreted in urine, $1-3 \%$ in expired air, and 3-8\% in the faeces. Influence on the kidneys has not been investigated adequately even though kidneys play a major role in their elimination from the body. Therefore the goal of this study was to elucidate the potential adverse effect of the commonly used pesticide bendiocarb on the structure and ultrastructure of kidneys after its oral administration to adult rabbits at a dose of $5 \mathrm{mg} / \mathrm{kg}$ body weight per day for 3 days.

\section{Materials and Methods}

The experiment was carried out on 54-day-old clinically healthy male rabbits (Oryctolagus cuniculus), of the breed Hyla-2, $(\mathrm{n}=20)$, of mean body weigh $2.0 \pm 0.20 \mathrm{~kg}$ from an accredited animal farm (Nitra, Slovakia). The rabbits were kept in cages ( 5 per cage) and provided standard diet O-10 Norm type, Slovakia and water $a d$ libitum. The animals were assigned to a control $(\mathrm{C}, \mathrm{n}=10)$ and experimental $(\mathrm{E}, \mathrm{n}=10)$ group. Experimental

Address for correspondence:

Viera Almášiová, PhD.

Department of Anatomy, Histology and Physiology

University of Veterinary Medicine and Pharmacy

Komenského 73, 04181 Košice, Slovak Republic
Phone: +421918967942

E-mail: viera.almasiova@uvlf.sk

http://actavet.vfu.cz/ 
animals received bendiocarb in the form of capsules ( $96 \%$ Bendiocarb, Bayer, Germany) per os, at a dose of $5 \mathrm{mg} / \mathrm{kg}$ daily for 3 days.

All rabbits were euthanized by thiopental (Thiopental Valeant $1 \mathrm{~g}, \mathrm{ICN}$, Czech Republic, $100 \mathrm{mg} / \mathrm{kg}$ of body weight) on day 3 of the experiment and tissue samples up to $1 \mathrm{~mm}^{3}$ were excised from cortical and medullar portions of kidney. The excisions were fixed by immersion in 3\% glutaraldehyde and postfixed in $1 \%$ osmium tetraoxide ( $\mathrm{pH} 7.2-7.4)$, dehydrated in acetone, and embedded in Durcupan ACM (Fluka). Semi-thin sections for light microscopy (LM) as well as ultra-thin sections for transmission electron microscopy (TEM) were cut using an ultramicrotome LKB Nova. The semi-thin sections were stained with toluidine blue, examined under a light microscope Zeiss Axio Lab A1. Ultra-thin sections were double contrasted with uranyl acetate and lead citrate, observed and documented by electron microscope Tesla BS 500.

Conditions of animal care and handling were approved by the Ethics Committee of the University of Veterinary Medicine and Pharmacy in Košice (No. 2647/07-221/5) and State Veterinary and Food Institute in Bratislava (No. 1827/09-221/3) followed Slovak protocols for ethical standards for the use of laboratory animals.

\section{Light microscopy (LM)}

After 3 days of carbamate treatment, the kidney cortex and medulla revealed moderate diffuse changes. The kidney corpuscles were regular and unchanged, but the uriniferous tubules and collecting ducts were invariably changed. The interstitium showed typical appearance. Detailed study of the kidney cortex revealed several alterations within the kidney parenchyma, involving especially the proximal tubules, distal tubules and cortical collecting ducts (Plate I, Figs. 1,2). The renal corpuscles were mostly globular or oval in shape. They were composed of the characteristic glomerulus and the double-layered Bowman's capsule.

The proximal tubules were lined with cuboidal epithelial cells. The cell nuclei were typically round and the basal part of the cytoplasm contained well developed elongated mitochondria. The apical portion of the cytoplasm contained more vacuoles than that of control counterparts, and the brush border was shorter and irregular. Occasionally the lumina of the proximal tubules contained sloughed epithelial cells with pale vacuolar cytoplasm (Fig. 1). The distal tubules were lined with tall cuboidal to columnar cells with typical round nuclei and basally located elongated mitochondria. The lumina of the distal tubules were cleft, or even missing, due to the presence of large pale vacuoles within the apical portion of the cytoplasm (Fig. 2). The cortical collecting ducts were lined with lower cuboidal cells that contained higher number of vacuoles within the cytoplasm. The cell nuclei were mostly oval in shape and irregular. Some sporadic sections contained also sloughed epithelial cells. The interstitium contained characteristic components and did not show any signs of inflammation (Fig. 1). The medullary portion of the kidney consisted of medullary collecting ducts lined with typical lower cuboidal dome-shaped cells. The cells had round, centrally located nuclei, and their cytoplasm contained small vacuoles. Some sections of the ducts showed epithelial sloughing (Plate II, Fig. 3). The thin limbs of the loops of Henle, the second important component of the renal medulla, were lined with typically flat epithelial cells. They contained relatively large oval nuclei and the cytoplasm only rarely contained small vacuoles. Some epithelial cells were necrotizing with a pycnotic nucleus and shrunk cytoplasm. The medullary interstitium was characteristic in its appearance (Fig. 3).

\section{Transmission electron microscopy (TEM)}

After 3 days of bendiocarbamate administration, the renal corpuscles did not show any apparent ultrastructural defects. The endothelium of glomerular capillaries was continuous with typical fenestrations, and the basement membrane showed a characteristic trilaminar structure. The podocytes were equipped with well developed system of rough endoplasmic reticulum, ribosomes, and mitochondria. The primary processes trabeculae and secondary foot processes pediculae of podocytes showed typical appearance. The cells lining the 
proximal tubules revealed several ultrastructural changes. Basal parts of the cytoplasm were occupied by short and sometimes swollen mitochondria. The basolateral plasma membrane infoldings were not as deep as in controls. The apical portion of cells revealed shorter and irregular microvilli and the cytoplasm contained a higher number of vacuoles. Some sporadic sections of the proximal tubules contained sloughed epithelial cells. These cells had either round or irregular shape, smooth surface without any microvilli, and the cytoplasm contained randomly oriented and swollen mitochondria (Plate II, Fig. 4). The most dominant feature within the cytoplasm of cells lining the distal tubules was the presence of large electronlucent apical vacuoles. The surface of cells was smooth without evident microprojections. The basally located mitochondria were shortened and often swollen. The basolateral infoldings of the plasma membrane were shallow (Plate III, Fig. 5). The medullary collecting ducts comprised two cell types. The first type: more numerous cells revealed more electrondense cytoplasm containing a high number of small electronlucent vacuoles located especially within the apical portion of cytoplasm (Plate III Fig. 6). The thin limbs of Henle's loops comprised oval-shaped cells with typical regular oval nuclei. Their cytoplasm possessed unchanged organelles, such as the mitochondria, rough endoplasmic reticulum, ribosomes, as well as a small number of randomly scattered vacuoles.

\section{Discussion}

The present study focusing on qualitative changes at the level of light and transmission electron microscopy of the kidney as the most important excretory organ, proved a negative effect of 3-day oral administration of bendiocarb. The above mentioned changes are consistent with observations of other authors who noted similar abnormalities in rats after subchronic administration by carbamates or organophosphates (Tós-Lúty et al. 2001; Salem 2011). The exfoliation and cellular necrotization which were the most serious defects observed in the present work were also noted by Lin and Garry (2011). Similar features in the kidney parenchyma were found in mice after endosulfan administration (Caglar et al. 2003).

The action reverses quickly once the exposure has passed because carbamates do not accumulate in tissues. Overall, carbamates easily pass across the cytoplasmic membranes and rapidly reach various tissues due to high solubility in lipids, are transformed in the liver and eliminated by urine or excrements. It is well known that there is a comparatively low risk of carbamates for mammals, which is based on their biodegradation (Sogorb and Vilanova 2002). The specific changes across kidney parenchyma most likely result from negative action of bendiocarb or its metabolites which are highly soluble in lipids, and the reactive oxygen species supposedly play a role in changing configuration of plasma membranes, and seem to account for degenerative alterations in kidney (Dias et al. 2013).

Neurotoxicity as the main impact of carbamates as well as alterations of homeostasis (Sobekova et al. 2009; Capcarova et al. 2010; Mojzi sova et al. 2012) or other important organs such as thymus (Flesarova et al. 2007), lymphoid tissue (Petrovova et al. 2010), liver (Holovska et al. 2011; Pollakova et al. 2012), spleen (Petrovova et al. 2011), and testes (Almasiova et al. 2012) have been studied in great detail.

The findings reported in the present study proved the negative influence of bendiocarb on the kidney parenchyma in rabbits.

\section{References}

Almasiova V, Holovska K, Tarabova L, Cigankova V, Lukacinova V, Nistiar F 2012: Structural and ultrastructural study of the rabbit testes exposed to carbamate insecticide. J Environ Sci Health A 47: 1319-1327

Caglar Y, Kaya M, Belge E, Mete UO 2003: Ultrastructural evaluation of the effect of endosulfan on mice kidney. Histol Histopathol 18: 703-708 
Capcarova M, Petrovova E, Flesarova S, Dankova M, Massanyi P, Danko J 2010: Bendiocarbamate induced alterations in selected parameters of rabbit homeostasis after experimental peroral administration. Pestic Bioch Physiol 98: 213-218

Challis IR, Adcock JW 1981: The metabolism of the carbamate insecticide bendiocarb in the rat and in man. Pestic Sci 12: 638-644

Dias E, Gomes M, Domingues C, Ramalheira E, Morais S, Perreira MDL 2013: Subacute effects of the thiodicarb pesticide on target organs of male wistar rats: Biochemical, histological, and flow cytometry studies. J Toxicol Environ Health A 9: 533-539

Flesarova S, Lukac N, Danko J, Massanyi P 2007: Bendiocarbamate induced structural alterations in rabbit thymus after experimental peroral administration. J Environ Sci Health B 3: 329-334

Holovska K, Almasiova V, Tarabova L, Cigankova V 2011: Effect of xenobiotics on the structure of the rabbit's liver. Folia Veter 55: 69-72

Lin N, Garry VF 2011: In vitro studies of cellular and molecular developmental toxicity of adjuvants, herbicides, and fungicides commonly used in Red River Valley, Minnesota. J Toxicol Environ Health A 60: 423-439

Mojzisova J, Massanyi P, Danko J, Trbolova A, Petrovova E, Mazensky D, Vdoviakova K, Luptakova L, Torma $\mathrm{N}$ 2012: Changes of the immunological and haematological parameters in rabbits after bendiocarbamate application. J Environ Sci Health A 47: 1244-1248

Petrovova E, Mazensky D, Luptakova L, Holovska K, Spalekova E, Massanyi P, Haladova E, Toth T 2010: Alterations in the rabbit lymphoid tissue after bendiocarb administration. J Environ Sci Health B 45: 719-728

Petrovova E, Massanyi P, Capcarova M, Zivcak J, Stodola L 2011: Structural alteration in rabbit spleen bendiocarb administration. J Environ Sci Health B 46: 788-792

Pollakova J, Kovalkovicova N, Csank T, Pistl J, Kocisova A, Legath J 2012: Evaluation of bendiocarb cytotoxicity in mammalian and insect cell cultures. J Environ Sci Health B 47: 538-543

Salem MM 2011: Toxic effects of mancozeb containing formulations and neemix pesticides on kidney function and ultrastructure of albino rats. Acad J Biol Sci 3: 17-30

Sogorb MA, Vilanova E 2002: Enzymes involved in the detoxication of organophosphorus, carbamate and pyrethroid insecticides through hydrolysis. Toxicol Lett 128: 215-228

Sobekova A, Holovska K, Lenartova V, Flesarova S, Javorsky P 2009 The another toxic effect of carbamate insecticides. Acta Biol Hung 60: 45-54

Tós-Lúty S, Przebirowska D, Latuszynska J, Tokarska-Rodak M 2001: Histological and ultrastructural studies of rats exposed to carbaryl. Ann Agric Environ Med 8: 137-144

World Health Organization (WHO) 2007: Data sheets on pesticides, No. 52, Bendiocarb, Bureau of Chemical standards, Environmental Health Directorate, Health \&Welfare: Canada

Available at: http://www.inchem.org/documents/pds/pds/pest52_e.htm. Last modified 2007. Accessed September 9,2014 
Plate I

Almášiová V. et al.: Structural... pp. 295-298

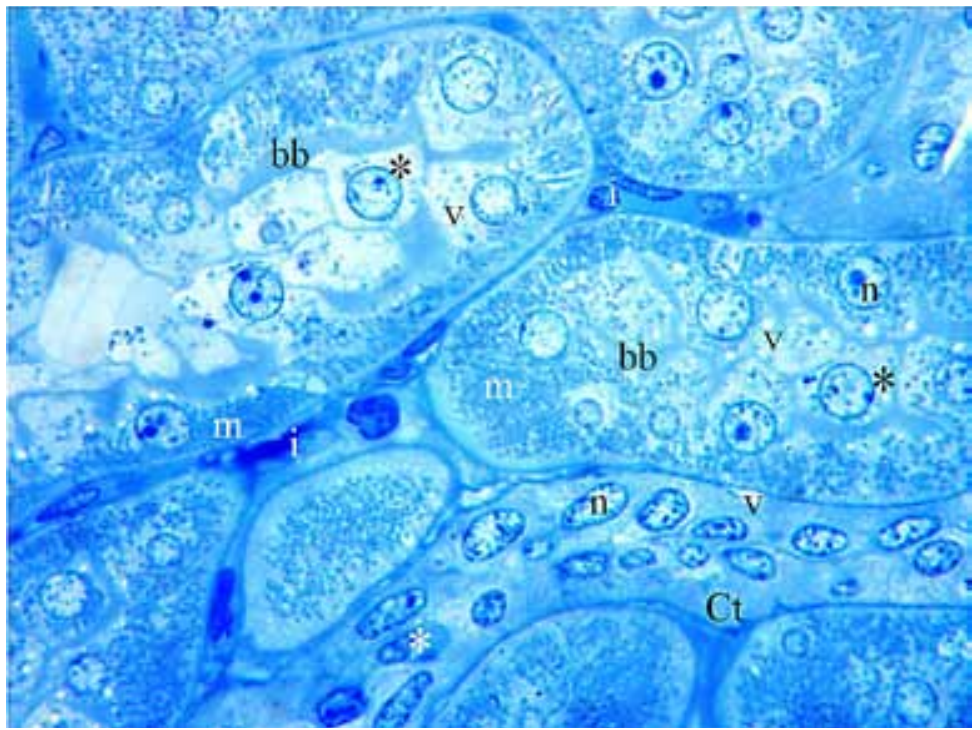

Fig. 1. Proximal tubules and the cortical collecting duct after 3 days' exposure to Bendiocarb (LM). Magnification $\times 400, *$ - sloughed cells, $\mathrm{v}$ - vacuoles, $\mathrm{n}$ - nucleus, $\mathrm{m}-$ mitochondria, $\mathrm{bb}-$ brush border, $\mathrm{Ct}$ - collecting tubule, $\mathrm{i}$ - interstitium

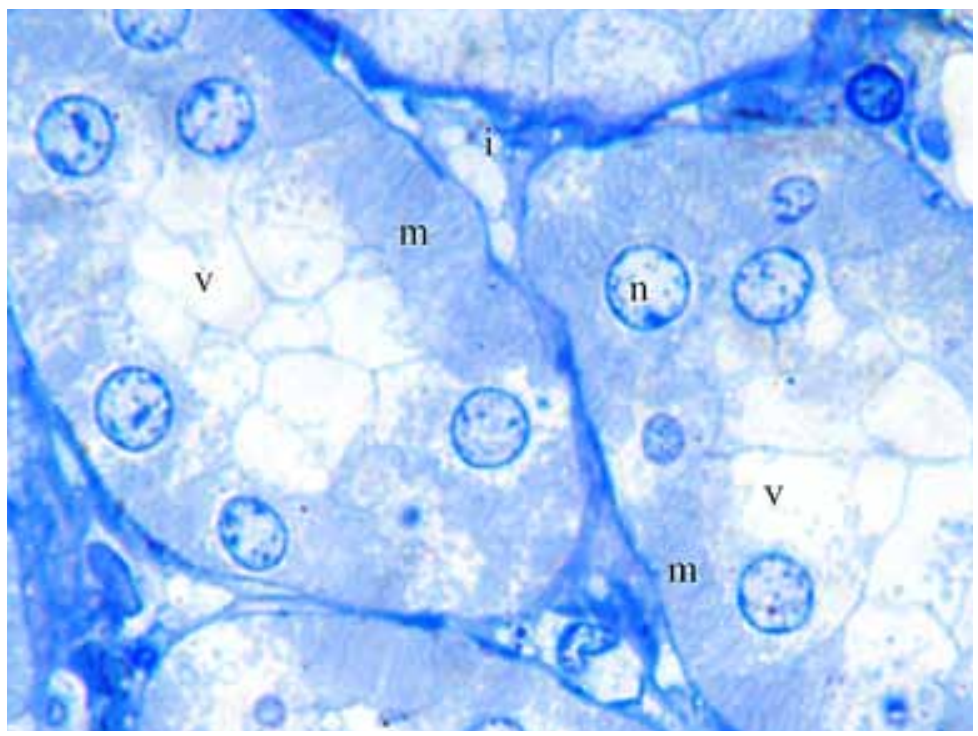

Fig. 2. Distal tubules after 3 days' exposure to Bendiocarb (LM).

Magnification $\times 1000, \mathrm{v}$ - vacuoles, $\mathrm{n}$ - nucleus, $\mathrm{m}$ - mitochondria, $\mathrm{i}$ - interstitium 
Plate II

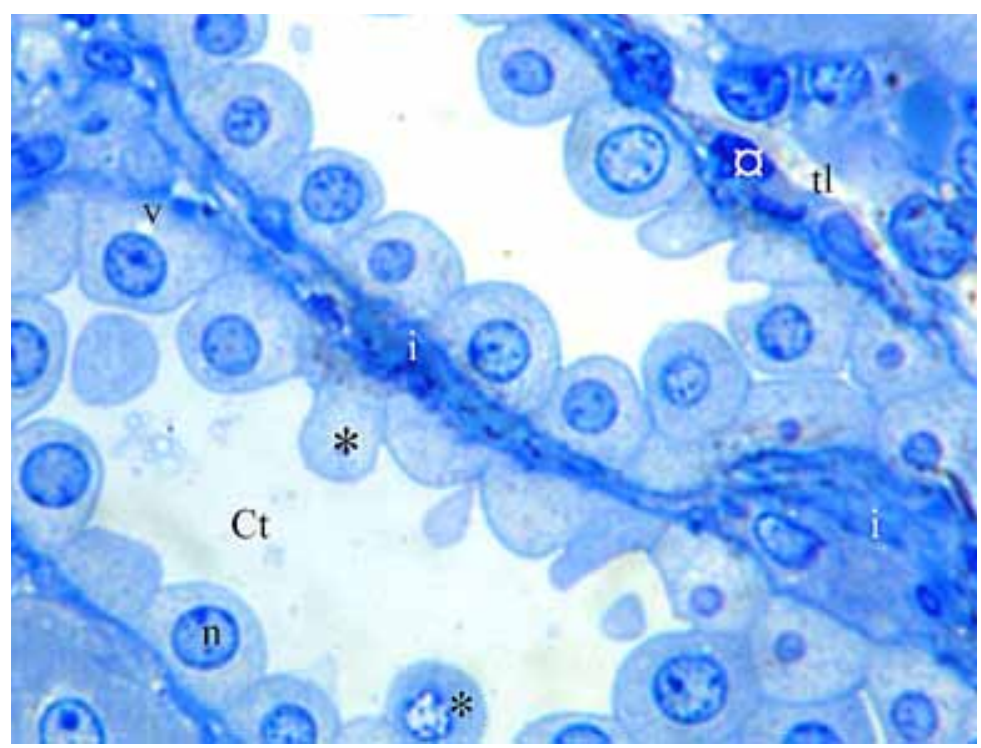

Fig. 3. Medullary collecting ducts and thin limb of the loop of Henle after 3 days' exposure to Bendiocarb (LM).

Magnification $\times 1000, \mathrm{Ct}$ - collecting ducts, $\mathrm{tl}-$ thin limb of the loop of Henle, $\mathrm{v}$ - vacuoles, $\mathrm{n}$ - nucleus,

* - sloughed cell, $a$ - necrotizing cell, $\mathrm{i}$ - interstitium

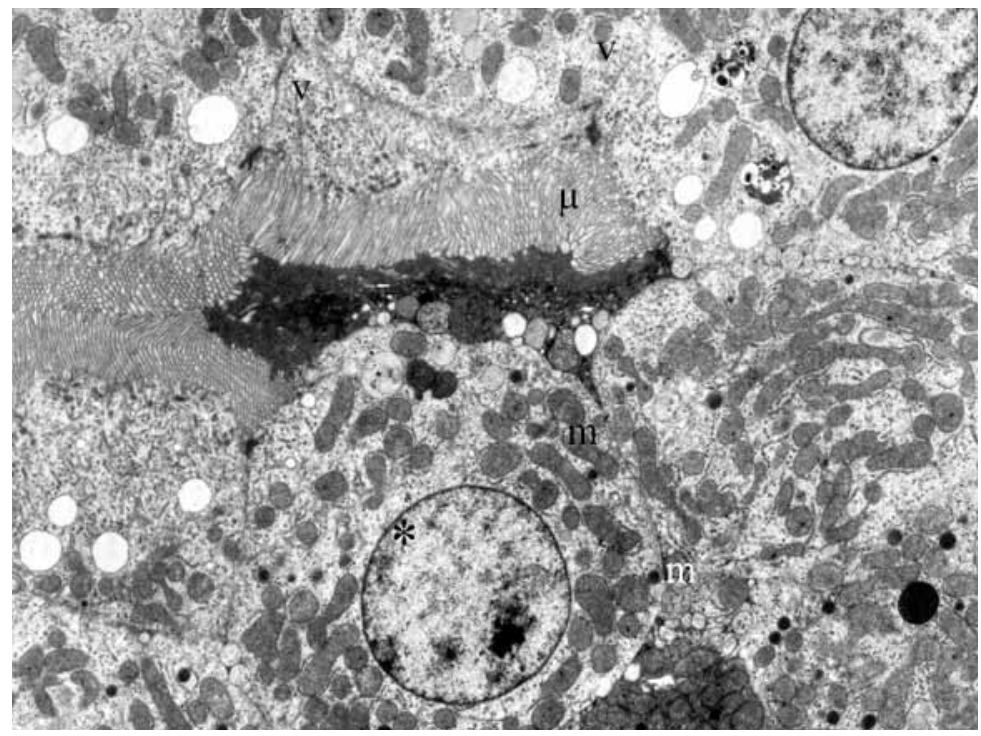

Fig. 4. Detail of the apical portion of the proximal tubule after 3 days' exposure to Bendiocarb (TEM). Magnification $\times 3800, \mathrm{~m}^{\prime}-$ swollen mitochondria, $\mathrm{v}$ - vacuoles, ${ }^{*}$ - sloughing cell, $\mu$ - microvilli 


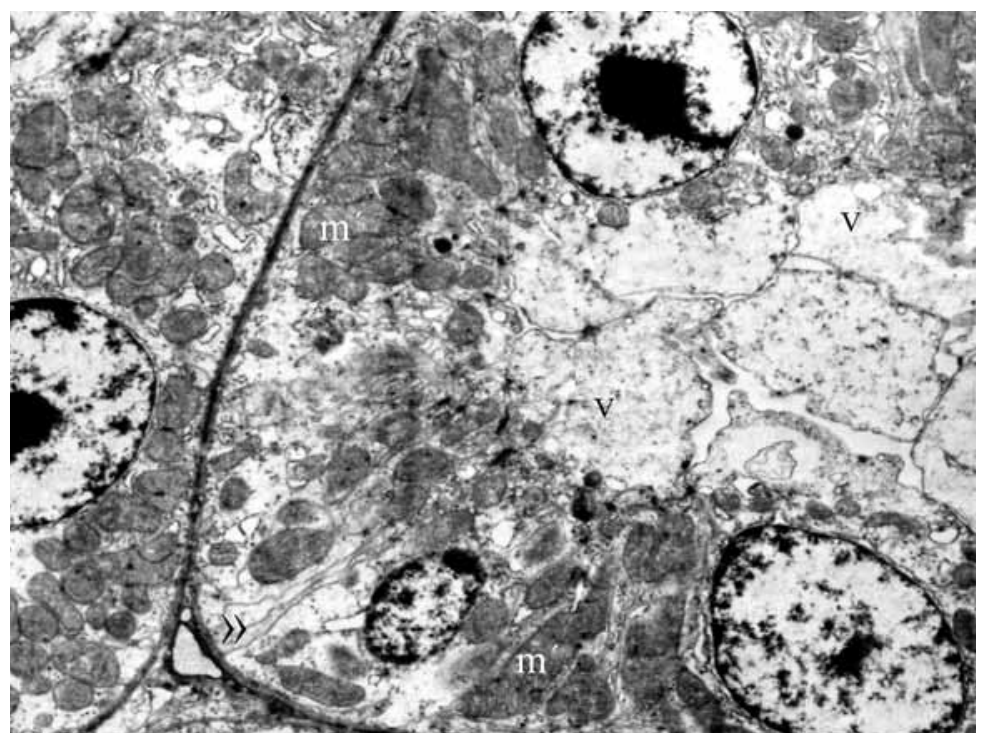

Fig. 5. Detail of the distal tubule after 3 days' exposure to Bendiocarb (TEM).

Magnification $\times 3800, \mathrm{~m}^{\prime}$ - swollen mitochondria, $\mathrm{v}$ - vacuoles, $»$ - shallow basolateral plasma membrane infoldings

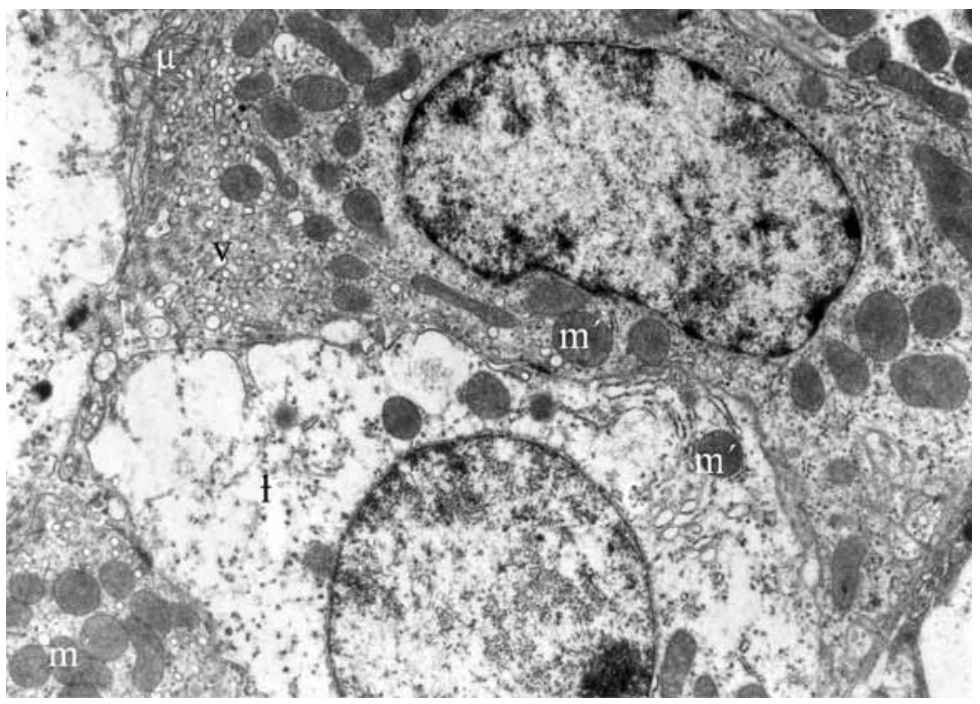

Fig. 6. Detail of the medullary collecting duct after 3 days' exposure to Bendiocarb (TEM). Magnification $\times 3800, \mathrm{~m}^{\prime}-$ swollen mitochondria, $\mathrm{v}-$ vacuoles, $\mu$ - short microvilli, $1-$ electronlucent cytoplasm with reduced organelles 